\section{Peak acid output}

R. Tauber und F. H. Perschel

Institut für Laboratoriumsmedizin, Klinische Chemie und Pathobiochemie, Charité - Universitätsmedizin Berlin Campus Virchow-Klinikum, Berlin, Deutschland

Synonym(e) PAO; Gipfel-Säuresekretion

Englischer Begriff peak acid output

Definition Der PAO entspricht der nach Stimulation durch Pentagastrin mit dem $\triangleright$ Magensaft während 60 Minuten sezernierten $\mathrm{H}^{+}$-Menge, ermittelt aus den 2 aufeinanderfolgenden Fraktionen mit der höchsten $\mathrm{H}^{+}$-Sekretion ( $\triangleright$ Magensekretionsanalyse).
Beschreibung Der PAO entspricht im Säuresekretionstest ( $\triangleright$ Calcitonin-Stimulationstest) weitgehend dem $\triangleright$ Maximal acid output (MAO), jedoch werden zu seiner Berechnung nur die beiden nebeneinanderliegenden 15-Minuten-Fraktionen mit der höchsten Säuresekretion berücksichtigt. Die $\mathrm{H}^{+}$Menge dieser beiden Fraktionen wird summiert und mit dem Faktor 2 multipliziert.

\section{Literatur}

Harris AW, Gummett PA, Misiewicz JJ, Baron JH (1996) Eradication of Helicobacter pylori in patients with duodenal ulcer lowers basal and peak acid outputs to gastrin releasing peptide and pentagastrin. Gut 38:663-667 